\title{
Assessing technology-based spin-offs from university support units
}

\author{
Mircea Epure \\ Department of Economics and Business, Universitat Pompeu Fabra and Barcelona GSE \\ $\underline{\text { mircea.epure@upf.edu }}$ \\ Diego Prior \\ Department of Business, Universitat Autònoma de Barcelona \\ diego.prior@uab.cat \\ Christian Serarols \\ Department of Business, Universitat Autònoma de Barcelona \\ christian.serarols@uab.cat
}

November 2011. This version: April 2014

Forthcoming in Regional Studies

\begin{abstract}
This paper takes a regional studies approach to assess spin-offs from a university-based technology transfer network. We first detect the regional objectives, inputs and outputs needed to assess spin-offs from support programmes. We then provide evidence on regional mechanisms for firm creation. We analyse spin-offs created at Catalan universities and find that many efficient spin-offs have formal technology transfer agreements, and emerge from technology-oriented universities. We also find that higher innovation levels and experience from the parent university are associated with higher efficiency, which is positively related to future fundamental profitability. Finally, we propose regional policy making and research directions.
\end{abstract}

Keywords: university spin-off; regional development; efficiency; entrepreneurship; technology transfer; innovation

JEL codes: M1, R1

\footnotetext{
${ }^{\ddagger}$ Corresponding author
} 


\section{Introduction}

This paper assesses the efficiency of spin-offs from a regional support programme. It first defines the regional institutions' objectives and next provides evidence on spin-offs created within a technology transfer network placed at Catalan universities. Implications are discussed in relation with the main spin-offs' characteristics such as employing university personnel, innovation and the degree of embeddedness in the support programmes. This research is thus rooted in the economics and management literature on generating innovation technology for regional development. More generally, this study is related to the importance of small and medium enterprises (SMEs), which many times stand at the centre of regional support programmes. Linked to this, early studies scrutinised the increasing number and many times improved survival rate of SMEs (e.g. Cromie 1991; Hawkins 1993; White and Reynolds 1996). Also, seminal research systematically investigated how policies for fostering start-ups impact positively on job creation (Birley 1987; Kirchhoff and Phillips 1988; Storey 1994), economic growth (Sexton 1986; Dubini 1989; Wennekers and Thurik 1999), or innovation (Drucker 1985; Pavitt et al. 1987; Acs and Audretsch 1988).

More recent studies indicated that SMEs increasingly originate through commercialising innovations from university research (Carayannis 1998; Siegel et al. 2003; Vohora et al. 2004; Clarysse et al. 2005; Lockett et al. 2005). Given their incentives for regional development, local institutions and universities introduced support systems for business creation. These efforts of public research institutions and the business sector to collaborate towards firm creation have been understood, following the influential contributions of Etzkowitz (1998; 2003; 2004), as the university's "third mission". This mission is predominantly present in European universities, which traditionally focused on teaching and academic research, while technology or knowledge transfer remained neglected. In this line, Etzkowitz designed the Triple Helix model to highlight that university, industry and institutions must cooperate towards the common goal of knowledge-based economic development. This objective is mostly pursued via spin-off firms that employ university knowledge or — more generally—via firms created at university-based support programmes.

University-based ventures were examined by a newer array of research jointly with arguments for regional development or wealth creation (Harmon et al. 1997; Hindle and Yencken 2004; Ma and Tan 2006). To name just a few findings, university spin-offs are sources of jobs, intermediaries between basic and applied research, or drivers of change towards a knowledge-based economy (Wright et al. 2004). Several single case papers qualitatively described the university spin-off phenomena (e.g. Jacob et al. 2003; Carayol and Matt 2004; Debackere and Veugelers 2005; Acworth 2008), but did not measure the efficiency of such firms or the relation between the support mechanisms' characteristics and efficiency. However, organisation studies usually assume that assessing efficiency represents a crucial aspect as it is closely linked to meeting financial targets and achieving regional sustainability and competitiveness. 
Building on this organisational performance justification, there is some scarce evidence from quantitative analyses of spin-offs' performance. Findings remain somewhat inconclusive. While Harrison and Leitch (2010) concluded that university spin-offs in Northern Ireland are not dynamic and remain small, Ortín-Ángel and Vendrell-Herrero (2014) analysed similar firms in Spain and found that they experience productivity growth. Nevertheless, these studies do not fully integrate the multiple regional objectives, partly due to their methodological approach. At a more macro level, a growing literature links efficiency with technology transfer. For instance, Chapple et al. (2005) used non-parametric Data Envelopment Analysis ((DEA), see Ray (2004) for details on this technique) to study the efficiency of UK university technology transfer offices (TTOs). They concluded that managers' business skills should be upgraded and found decreasing returns to scale indicating that TTOs should be smaller. Contrasting results are reported by Siegel el al. (2003) who employed parametric frontier methods and revealed that TTOs experienced constant returns to scale. A more comprehensive study of the efficiency of university technology transfer is included in Anderson et al. (2007). These authors employed DEA and found significantly higher technology transfer efficiency in leading universities and scrutinised differences between public versus private universities. On a related note, DEA was also used to estimate the efficiency of small manufacturing firms (Alvarez and Crespi 2003) or of science parks (Thursby and Kemp 2002), and more recently was indicated as an appropriate way to operationalize innovative entrepreneurial opportunities (Anokhin et al. 2011).

We build on these latter research streams and tackle various existing challenges from a regional studies perspective. A key task is to properly identify which resources (inputs) are used to produce regional value (outputs). Managerial economics literature conjectures that superior performance and competitive advantages emerge from resource configurations and firm practices (or routines). This framework is better known under the label of the resource-based view (Penrose 1959; Wernerfeldt 1984; Barney 1991; Peteraf 1993) or the more recent routines and capabilities approach (Teece et al. 1997; Teece 2007; Grant 2008). These theories start from identifying the available resources and related production possibilities, which are crucial when the analysed sample is specific in terms of the regional context and infrastructure characteristics. Also, under these frameworks the outputs and the underlying input-output relation (i.e. the routines) are strictly linked to the pursued objectives and organisational characteristics. For instance, the outputs that are important from a regional viewpoint need to be measured according to regional institutions' objectives. Failure to do so could lead to inconclusive results, as support programmes provide resources that alter the incentives for technology transfer, in the absence of which universities may simply pursue other goals.

Therefore, we propose to use a suitable efficiency measure that accurately assesses the objectives of regional policy making institutions, while integrating the firm value producing activities. In the short run, the main firm objective is aligned with the regional goals. That is, the entrepreneur's target is to increase the probability to survive by maximising revenues. Additionally, regional support institutions desire to create patents - that are usually believed to have a positive impact on long run 
development - and generate jobs with as low budgets as possible. This latter constraint on regional policy making is of current interest, as the financial crisis required many local administrations to cut budget spending. Indeed, the Spanish press consistently indicated that cutting R\&D funds was a priority within the deficit control measures. Given this multidimensionality, the usual methods (e.g. productivity and profitability ratios, or even traditional DEA assessments) are not appropriate.

To account for the various regional goals, we use a particular nonparametric frontier-based distance function. This method simultaneously expands multiple outputs and contracts multiple inputs, and thus can unify the regional institutions' objectives in a unique measure. Moreover, the estimation method provides benchmarking information, as firm-level efficiency is computed with respect to the best practice frontier. Benchmarking-type feedback is appealing to policy makers, who can observe which types of spin-offs use resources more efficiently, jointly with their university of origin and characteristics. Second stage analyses enhance the interpretations that emerge from the efficiency measure. Specifically, regressions are estimated to reveal how key spin-offs' characteristics are related to efficiency, and whether higher efficiency is associated with profitability.

We first theoretically postulate and systematically argue that the variables' definition should match the specific regional goals. From this perspective, the multiple outputs to maximise include revenues, patents and jobs. At the same time, the inputs to minimise depend on the support programmes and other private funding. In this sense, the inputs (e.g. funding received, infrastructure used) define the regional sample's specificity. Second, we postulate that certain spin-offs' characteristics are positively related to their efficiency. Among these, we emphasize the use of university personnel, generating patents and the degree of embeddedness in the university support programmes. Finally, we test whether higher efficiency from a regional perspective is positively linked to fundamental profitability in the subsequent years.

Consequently, this paper contributes to the regional studies literature in at least two ways. First, it detects and conceptualises the specific regional objectives and the associated inputs and outputs needed to assess firms created at university-based support units. Second, an application provides empirical insights into regional mechanisms for firm creation. To reach these goals, a particular sample of spin-offs created within the so-called Technological Trampolines' (TTs) placed at Catalan universities is evaluated. ${ }^{1}$ This Spanish region has developed various R\&D programmes, among which the regional TT network offers an ideal research setting. Most importantly, firms created within this programme have benefited from various types of support in infrastructure and monetary terms.

Main results indicate that many efficient spin-offs have formal technology transfer agreements and emerge from more technology-oriented universities. Furthermore, higher innovation levels and experience or knowledge (personnel) from the parent university are associated with higher efficiency. Also, efficiency is positively related to fundamental profitability in the second subsequent year. Our

\footnotetext{
${ }^{1}$ TTs are support units integrated —in the Catalan case—in TTOs. Section 3 describes them in more detail.
} 
conclusions propose regional policy making and future research lines. There are some limitations to our study. Due to the specificity of the support programme and the employed variables, the sample is restricted to data available on spin-offs from Catalan universities. While we add data on survival and profitability for subsequent years, the proposed multidimensional efficiency measure cannot be computed for a panel. These restrictions also limit the possibilities of comparing the assessed spinoffs with reference groups. However, we can comprehensively compare efficiency from a regional perspective within the sample, between the various firm characteristics and universities of origin. Reaching these in-depth regional interpretations differentiates our study from the contributions of, e.g., Harrison and Leitch (2010) or Ortín-Ángel and Vendrell-Herrero (2014).

The remainder of the paper is ordered as follows. The regional context and data are described in Section 3. Next, Section 4 presents the efficiency measure and employed variables jointly with the main analysis stages. The discussion of the empirical results and the derived conclusions and implications are developed in Sections 5 and 6, respectively. To set the ground for the remainder of the paper, Section 2 presents some theoretical underpinnings.

\section{Theoretical underpinnings}

This section takes a managerial economics approach to set the theoretical foundations for operationalizing the regional objectives and variables required for assessing firms that benefit from support programmes. We start by assuming that efficiency from a regional perspective is a function of, or can be partially explained using, differences in resources (i.e. inputs). Probably the most extensively used framework that proposes and sustains this assumption is the resource-based view (Penrose 1959; Wernerfeldt 1984; Barney 1991; Peteraf 1993). Managerial economics literature developed this approach to suit in-depth analyses that integrate not only the concept of unique resource bundles, but also organisational practices or routines used for transforming inputs into outputs. Competitive advantages and differences in efficiency are expected to spur from core operational processes under what is best known as the routines and capabilities framework (Teece $e t$ al. 1997; Teece 2007; Grant 2008). This study scrutinises the process of combining resources in novel ways, as called for by recent contributions (see, e.g., Denrell et al. 2003; Foss and Ishikawa 2007). The many times ignored component is that for evaluating resources and routines given by inputoutput relations, one must also have the capacity to analyse the performance of competitors in a given (regional) environment (Denrell et al. 2003). These missing element can be addressed using distance functions, and a regional focus for defining objectives and related inputs and outputs.

While in essence these views are compatible with many managerial economics approaches, the regional context requires a few applied considerations. Foremost, we are dealing with a particular sample which is difficult to benchmark against firms from other regions or even firms from the same region that did not benefit from the university-based support programme. The analysed spin-offs use 
region- (or institution-) and unit-specific resources, directly implying that their inputs define a homogenous technology that must be specified as given by the regional and TTs settings. ${ }^{2}$ Using resource-based view conceptual lenses, we identify these inputs in the related literature, and match them with regional objectives (i.e. the outputs). Furthermore, once the variables are operationalized, the input-output relationship represents the net effect of organisational practices (or routines). These resources and input-output routines are firm-specific, but largely determined by the regional context. This view stems from perceiving spin-offs as a manner to exploit intellectual property emerged from science and embedded in parent organisations (see Mustar et al. (2006) for more details). In addition, our regional emphasis is even stronger, since the analysed organisations are in their turn rooted in the Catalan environment that is believed to positively influence industrial growth and innovation capabilities (see Ahedo (2006) or Buesa et al. (2006)). ${ }^{3}$

Business start-ups in university contexts are conditioned by several factors (Di Gregorio and Shane 2003; Nicolaou and Birley 2003; Siegel et al. 2003; Clarysse et al. 2005; Debackere and Veugelers 2005). Key regional and institutional factors, or simply drivers of spin-offs' promotion, include the availability of venture capital in the university area (Di Gregorio and Shane 2003), the university reward system (Nicolaou and Birley 2003), the bureaucracy and inflexibility of university administrators (Siegel et al. 2003) or the resources of the TTOs (Clarysse et al. 2005). It is worth stressing that these studies did not specifically attempt to evaluate the performance of spin-offs from support institutions similar to the Catalan TTs and therefore do not provide a set of operationalized variables. We thus propose that in-depth analyses of firms created via support programmes should account for regional development inputs, such as economic aid or infrastructure use.

Note that even in the presence of positive market conditions for firm creation, there have been various attempts to justify why universities and regional institutions should invest in generating spinoffs. Matkin (1990) stated three core ones: reasons related to the academic staff, economic reasons and technology transfer. The first type of reasons, many times overlooked in the literature, indicate that creating a new venture could retain a scholar with commercial interests, whom otherwise might leave the institution. In line with this assumption, we propose to evaluate the relation between using university personnel and firm efficiency from a regional perspective. Moreover, evidence indicates that creating spin-offs is more profitable for inventors than external licensing to established companies (Wright et al. 2004). This integrates well with the economic reasons, as profits obtained by universities through equity ownership are expected to be greater than royalties from sales.

The reasons related to the impact of technology transfer are more straightforward. Spin-offs usually increase the number and amount of research contracts with universities, particularly in their

\footnotetext{
${ }^{2}$ See sections 3.2 (Sample) and 4.2 (Inputs, outputs and final sample) for more details on this statement. Obviously, this study can be replicated for other regions. However, in those cases the variables' operationalization should be transposed to the new context and more primary data would be required.

${ }^{3}$ Yet another review for the Catalan context - but of a qualitative nature and therefore not aiming at assessing efficiency — can be found in Serarols et al. (2009).
} 
initial phases of development, because they often externalise their R\&D activities (Pérez and Martínez 2003). As a result, technology transfer is expected to positively influence teaching and research by creating opportunities for doctoral theses or master's degree projects. However, and on the one hand, there is literature that empirically demonstrates a non-significant or even negative relationship between technology transfer and regional contribution. For example, Harmon et al. (1997) showed that technology transfer processes were successful, but without any substantial evidence that they significantly contributed to both new business and job creation. Additionally, scholars and policy makers are warned to be cautions with the notion that new or high technology firms will have any direct economic impact (Harmon et al. 1997).

On the other hand, as aforementioned, entrepreneurship research most often assumes — or does not question - the importance of university spin-offs. Nor does it investigate in detail the potential dissimilarities that may exist between spin-offs from the same or different support institutions. One can find in the entrepreneurship literature statements such as "spin-offs create wealth" (Hindle and Jencken 2004; Wright et al. 2004; Mustar et al. 2006), "spin-offs create jobs" (Steffensen et al. 2000; Clarysse et al. 2005) or other similar statements on the general idea that spin-offs provide many benefits to universities and the region. In this array of literature spin-offs are always seen as valuable entities that play a key role in enhancing local economic growth and foster job and wealth creation, all of which are closely related, or emerge from, innovation and management practices (Ireland et al. 2001; Shane 2004). Yet again, the role of university personnel seems crucial given its direct relation to innovation and, on most occasions, to the spin-offs' administrative tasks. We thus postulate that a positive relation exists between employing university personnel and firm efficiency.

The caveat of most reviewed studies is that they fail to give a definitive answer to how to empirically assess spin-offs' efficiency. Problems with evaluating spin-offs from the regional institutions' standpoint may well appear when variables are not defined systematically. We propose that one should carefully account not only for the usual firm inputs and outputs but - and more important for the objectives at hand-for regional variables that directly support spin-offs, and for variables that foster regional growth. For instance, in the absence of institutional support for technology transfer, universities may simply lack the correct incentives for spin-off creation, and direct their efforts only towards teaching and research.

Through our proposals and assumptions we reach a basic research design based on the appropriate variables for assessing the efficiency of firms from university-based support programmes. We first identify the regional objectives of the promoting institutions. These can be broadly expressed as enhancing regional development, with economic growth as a central factor. In addition, regional policies usually adopt a twofold perspective: wealth and job creation. In the specific case of university spin-offs, innovation - measured via patents generated - plays an essential role. While pursuing these objectives, regional institutions offer several types of assistance (resources). These can also be categorised into two blocks, and follow our proposition to account for economic and infrastructure 
aid. First, the most common resources consumed for incentivising spin-offs' creation are the grants and other financial aids. Institutions employ these channels to increase the firms' capital, a main contributor to the productivity growth of (Spanish) regions (Badunenko and Romero-Ávila 2012). Second, various services can be offered to spin-off companies (e.g. free use of infrastructure or needed technology) to ease the early development processes.

We can now propose the variables' categories that that are operationalized and defined in detail in Section 4.2. We isolate inputs (resources) such as grants or economic aid and external services (from the regional institutions), and funds received from contracts and expenditures (traditional economic and accounting variables). As a natural output for firm and growth we can consider the firms' revenues. Regional and institutional-specific outputs are the number of patents generated and the number of jobs created. In-depth assessments should include all these dimensions and be flexible enough to allow for productive specialization, which was previously found to have a close relationship with the efficiency of Spanish regions (Maudos et al. 2000). Finally, according to our propositions, the level of innovation and the type of employed personnel potentially affect spin-off efficiency and hence we scrutinise this relation (Ireland et al. 2001; Shane 2004).

\section{Regional context and data}

\subsection{Regional environment and the Technological Trampolines}

Catalonia is situated in the northeast of Spain, includes one sixth of country's population (about seven and a half million inhabitants) in an area of 32,114 square kilometres (out of the country's 505,992 square kilometres). Before the financial crisis it generated around 35\% of high-technology exports, $22.5 \%$ of the R\&D expenses and approximately a quarter of the industrial GDP (CIDEM 2006). Even in 2009 Catalonia's R\&D spending was of $1.7 \%$ of GDP, and the region employed about 46,000 researchers (ACC1Ó 2011). Additionally, its innovation expenses are extensively sustained through the business sector. ${ }^{4}$ Note at this point that we do stress that this study can be transposed to other regions or support programmes, situation in which one should identify the corresponding institutions and apply our research design to their characteristics.

In Catalonia - similarly to most other regions - the "third mission" is principally based on commercialising research. The academia-business interaction is mediated at regional level by the Centre for Innovation and Business Development (CIDEM, now named ACC1Ó), the initiator of the Technological Trampolines (TTs) project. The CIDEM was created in 1999 by the regional government to enhance the competitiveness of Catalan SMEs, mostly through innovation policies. Our interest is in one of its programmes: the university-level support for venture creation (CIDEM

\footnotetext{
${ }^{4}$ One can refer to ACC1Ó (2011), Serarols et al. (2009) or Criaco et al. (2013) for more detailed information on these issues as well as the TTs. We present here only the main characteristics and support programme mechanics of specific interest for our study.
} 
2006). Within this mechanism, the CIDEM founded the so-called TTs to encourage and sustain business creation. These promote technology- and knowledge-based spin-offs from the academia, having as main objectives to detect, select, evaluate and offer advice to new projects. TTs usually provide services as: seminars or workshops to explain entrepreneurial activity, office spaces and related infrastructure, feed-back on business projects, assistance and management of intellectual property rights, and information and support for applying for public funding.

TTs were developed during the 2000s and are independent entities integrated in public universities. TTs have separate budgets from universities and the CIDEM funds all their activities apart from the necessary physical assets, provided by the university at no charge. Moreover, TTs have certain technological orientations and must follow the directions given by the CIDEM when choosing which spin-offs to support. In general, selected projects incorporate differentiating or unique technologies and are oriented towards global markets. The TT network has ten units located at different universities, all coordinated by the CIDEM. ${ }^{5}$ Between 2001 and 2007 the CIDEM spent around 6,656,000 Euros (mostly as personnel expenses) for funding the TT network. Somewhat in parallel, the CIDEM granted 10,180,000 Euros in participative loans, 2,396,000 Euros in other grants, and participated in a venture capital projects that invested 2,199,000 Euros in spin-offs.

Whereas the CIDEM forms part of the public system, spin-offs sometimes receive support from other actors. These may be venture capitalists in search of profitable projects or foundations that promote entrepreneurship. It is thus important to also account for funding received from sources external to the regional support programmes, but embedded in the regional business environment. Jointly with the support of public and private institutions, this process of spin-off creation is grounded in the regional culture and attitude towards entrepreneurship. This further backs the proposition that the CIDEM and the TT programme cope better with the context and encompass the regional values.

\subsection{Sample}

The database is drawn from a specific project developed for the innovation support structures of the Catalan region. ${ }^{6}$ A two-step methodology was used to build the sample. First, a qualitative stage validated the underlying research design and the questionnaire for the data gathering. For the second stage, all spin-offs created within the TT network placed at Catalan universities were considered. These were a total of 335 firms, out of which the valid registers, after excluding deceased and unreachable firms, were 262. Primary data were gathered during 2007-2008 through structured

\footnotetext{
${ }^{5}$ The ten universities that participate in the TT project are: IESE, Universitat Autònoma de Barcelona (UAB), Universitat de Barcelona (UB), Universitat de Girona (UdG), Universitat de Lleida (UdL), Universitat Oberta de Catalunya (UOC), Universitat Politècnica de Catalunya (UPC), Universitat Pompeu Fabra (UPF), Universitat Ramon Llull (ESADE and La Salle) and Universitat Rovira i Virgili (URV).

${ }^{6}$ Another paper that uses TT data is Criaco et al. (2013), which does not adopt neither a regional studies nor an efficiency analysis orientation and has fundamentally different methodology and objectives from ours. Also, their use of the data is cursory with respect to the variables of interest for efficiency measurement.
} 
telephone and self-administrated Internet surveys. For the core part of the questionnaire, respondents had to indicate the services used from the TTs, jointly with key financial and other types of data on founding team, employees and all types of economic aid obtained. This process yielded 94 valid questionnaires (i.e. with complete answers to all questions necessary for this study). The financial information provided by the participants was validated and complemented using the SABI database. ${ }^{7}$

The survival rate of these analysed firms at the end of the year 2011 was of approximately $73 \%$, a very promising figure for the support programme considering the well-known financial distress endured during 2008-2011. The oldest firms in the sample were created in 1998 and the youngest in 2007. Nevertheless, more than $86 \%$ of these spin-offs were created after 2002 . They have on average between 6 and 7 employees ( 2 to 3 of which represented personnel from the parent university). Therefore, the sample comprises very young and small technology-based spin-off firms. In addition, it includes three activity areas: (a) technological sciences (i.e. computer science and engineering, 73 firms), (b) bio-chemical industries (i.e. pharmaceutical, biological or chemical industries, 16 firms), and (c) firms dedicated to employing technology in the social sciences area (5 firms).

When collecting data, the researchers noticed that some of the spin-offs in the sample did not completely fulfil Pirnay et al.'s (2003: 356) definition, according to which university spin-offs are "new firms created to exploit commercially some knowledge, technology or research results developed within a university". That is, various entrepreneurs stated that, even if they had received support from the TTs placed at Catalan universities, they did not have a clear relationship with the parent university; they just wanted assistance in applying for public funds. Others suggested that they were not exploiting technology developed within the university. However, cross-checking across the available data clearly indicated that for all cases there was an obvious practical (and not only theoretical) link between each firm and a certain university belonging to the TT network. Having this in mind, the traditional definition was revised to include three different groups of spin-offs:

- Group 1: Spin-offs with formal technology transfer agreements (STTU). ${ }^{8}$ These spin-offs have a formal technology transfer agreement with the parent university (e.g. patents, know-how contracts, equity, or contract research). Thus, this group fulfils to a complete degree most definitions that can be found in the literature.

- Group 2: Spin-offs that incorporate personnel from the parent university (SPU). ${ }^{9}$ These spin-offs integrate at least one member from the parent university within their current staff or founding team. This group does not include firms that have formal technology transfer agreements with the parent university. However, these firms do employ technology that was developed within a certain

\footnotetext{
${ }^{7}$ The SABI (Sistema de Análisis de Balances Ibéricos) database is provided by Bureau van Dijk and includes detailed financial statements, as well as other variables for Spanish enterprises.

${ }^{8}$ This is equivalent to the "direct research spin-offs" identified by Hindle and Yencken (2004).

${ }^{9}$ This is equivalent to the "indirect spin-off" identified by Nicolau and Birley (2003).
} 
university placed within the TT network and their activity is run at least partly by university members. Hence, SPUs fulfil to a medium degree most definitions in the literature.

- Group 3: Other spin-offs (OSU). According to the responses received during the primary data gathering, this group does not incorporate members from the parent university, nor does it have any formal agreement with the parent university. In this sense, firms in this category are not the usual spin-off firms and therefore we call them other spin-offs since they do appear in the TT network database. We do consider them spin-offs - even if they are less so than STTUs and SPUs - given that these are start-ups were placed and developed at a certain university of the TT network where they received infrastructure support and funding from the programme. Additionally, the researchers who compiled the database have had, jointly with the official information from the TTs, indications that these firms indeed benefited from support from the universities of origin within which they continued to be embedded.

[Figure 1 about here]

Once set the theoretical classification of the spin-offs, it is of pivotal importance to understand how all firms fit into the analysed sample, jointly with their interpretation according to the theoretical underpinnings. Figure 1 illustrates how the three types of spin-offs are embedded in universities and TTs. The first rationale is that all firms benefited from TT support and are specifically linked to a university of origin from the TT network. This defines their specific (and homogenous) technology in terms of available resources (i.e. inputs and know-how) and outputs desired by regional support institutions. ${ }^{10}$ Thus, they are comparable among each other, but not suitable for benchmarking against other types of firms that did not receive TT support.

The second rationale makes a similar point but is further integrated in our theoretical underpinnings. Figure 1 shows how each type of firm makes use of resources and capabilities (i.e. know-how) available from the universities and TTs. Foremost, all firms have access to the same type of funding and infrastructure support, and differ only in terms of their embeddedness into the university-TT mechanism. In inverse order with respect to our above classification, OSUs are the less embedded firms, as they make use of the general infrastructure, funding and know-how. SPUs, add to these general resources and capabilities, the specificity of the university human capital that is integrated and then maintained within the firm. Finally, STTUs not only use the general and human specific resources and capabilities, but also include a more formal contractual perspective through the technology transfer agreements they have stipulated with the parent university.

\footnotetext{
${ }^{10}$ The inputs and outputs—generally defined in the section on theoretical underpinnings—are described in detail in Section 4.2.
} 


\section{Efficiency measure, variables and stages of analysis}

\subsection{Efficiency measure: The proportional distance function}

TT networks represent complex settings that pursue multiple regional objectives, but act uncertain environments. On the one hand, this implies that various outputs must be expanded simultaneously, while also controlling for input quantities. On the other hand, efficiency levels should be provided accurately even if the real technology distribution is unknown. In these conditions literature usually employs non-parametric efficiency measures based on DEA (see Ray (2004) for detailed descriptions). These methods approximate true but unknown technology frontiers. Also, since they are non-parametric, no a priori technological restrictions are imposed on the sample distribution and no availability of prices is necessary. DEA computes the degree of inefficiency separating a certain firm from the best practice efficiency frontier. In this sense, frontier analysis is a more complex technique for benchmarking the relative performance of firms. Moreover, as opposed to single ratio methods, these technical efficiency estimations permit either to expand various outputs with no more inputs, or to contract various inputs maintaining the output level constant.

However, this last characteristic of traditional efficiency estimators represents a shortcoming for our analysis. That is, from both the TT network's and the spin-offs' perspectives, output expansion is a desired objective. Nevertheless, for the regional institutions, simultaneous input contraction is of equal importance. Efficient input use is a crucial aspect for the support programmes that aim to obtain the maximum amount of output with the minimum provided aid. This policy angle is of increased importance on the background of the recent financial crisis, which forced local administrations to cut budget spending in all areas. Actually, many press articles from leading Spanish newspapers indicated during 2010-2012 that cutting R\&D spending was a priority for the deficit control measures.

One solution is to utilise the directional distance functions proposed by Chambers et al. (1996). The advantage of these directional functions is that, instead of focusing only on input or output orientation (as traditional DEA measures do), they account for output expansions and input contractions simultaneously. Within this family of distance functions a special case is represented by the proportional distance function defined by Briec (1997). This function is especially useful for analyses that account for firm-specific characteristics, since each unit chooses its specific direction when measuring its performance against the best practice frontier.

Let $\mathbf{x}=\left(x_{1}, \ldots, x_{N}\right) \in R_{+}^{N}$ and $\mathbf{y}=\left(y_{1}, \ldots, y_{M}\right) \in R_{+}^{M}$ be the vectors of inputs and outputs, respectively, which form the technology $T$, representing the set of all output vectors $(\mathbf{y})$ that can be produced using the input vector $(\mathbf{x})$ :

$T=\{(\mathbf{x}, \mathbf{y}): \mathbf{x}$ can produce $\mathbf{y}\}$.

Following Briec (1997: 105), the proportional distance function to estimate the efficiency of firm $k^{\prime}$ is defined as: 


$$
D\left(x^{k^{\prime}}, y^{k^{\prime}}\right)=\max _{\delta}\left\{\delta:\left((1-\delta) x^{k^{\prime}},(1+\delta) y^{k^{\prime}}\right) \in T(\mathbf{x}, \mathbf{y})\right\}
$$

or as the solution to the following linear programming problem:

$$
\begin{array}{ll}
D\left(x^{k^{\prime}}, y^{k^{\prime}}\right)=\max \delta \\
\text { s.t. } & \sum_{k=1}^{K} \lambda^{k} y_{m}^{k} \geq y_{m}^{k^{\prime}}+\delta y_{m}^{k^{\prime}}, \quad m=1,2, \ldots, M ; \\
& \sum_{k=1}^{K} \lambda^{k} x_{n}^{k} \leq x_{n}^{k^{\prime}}-\delta x_{n}^{k^{\prime}}, \mathrm{n}=1,2, \ldots, N ; \\
& \sum_{k=1}^{K} \lambda^{k}=1 ; \\
& \lambda^{k} \geq 0(k=1,2, \ldots, K) .
\end{array}
$$

Note that this specification assumes variable returns to scale, an important issue when dealing with firms of different sizes that develop their activity in dynamic sectors. Efficient firms are indicated by a score of 0 (i.e. $\left.D\left(x^{k^{\prime}}, y^{k^{\prime}}\right)=0\right)$, while the inefficiency degree of units below the best practice frontier is shown by positive values of $D\left(x^{k^{\prime}}, y^{k^{\prime}}\right)$. Figure 2 illustrates the proportional distance function assuming a simple technology of one input and one output.

[Figure 2 about here]

Observe that points $\mathrm{A}, \mathrm{B}$ and $\mathrm{C}$ form the best practice convex efficiency frontier, whereas the rest of the (inefficient) units are enveloped below this frontier. For instance, to reach the frontier, points $\mathrm{D}$ and $\mathrm{E}$ must expand outputs and contract inputs as shown by the positive results (i.e. the inefficiency degrees) of $D\left(x^{D}, y^{D}\right)$ and $D\left(x^{E}, y^{E}\right)$, respectively. The directions of these two functions are given by the proportional expansion (contraction) of the employed outputs (inputs). Moreover, the efficiency results consider convex combinations on the best practice frontier as benchmark points.

\subsection{Inputs, outputs and final sample}

Inputs and outputs are specified according to the theoretical underpinnings in Section 2 and our specific dataset. We evaluate performance from two regional standpoints: scrutinising firms as fund receivers and as creators of regional value. Figure 3 illustrates the variables that can be classified into three categories and shows how these enter the efficiency measure as inputs or outputs: (a) inputs from regional support institutions and other production inputs for economic growth, (b) commercial outputs that are main firm-level economic growth objectives but also produce regional development, and (c) desirable outcomes from the public policy perspective (i.e. job generation for regional development). Considering the regional goals, category (a) is used as inputs, while categories (b) and (c) are outputs for the efficiency analysis. Descriptive statistics corresponding to inputs and outputs are shown in Table 1.

[Figure 3 and Table 1 about here] 
In Figure 3-similarly to the equations in Section $4.1-x_{1}$ to $x_{4}$ represent the inputs, whereas $y_{1}$ to $y_{3}$ denominate the outputs. Let us sequentially explain the source and content of each of the seven variables. The first two inputs, grants (or similar economic aid) $\left(x_{l}\right)$ and services used (i.e. university and TT network infrastructure) $\left(x_{2}\right)$ are provided by the regional support institutions. $x_{1}$ is the absolute monetary value of the funds received directly via the TT programme. For the services used $\left(x_{2}\right)$ data included only aggregated monetary values jointly with the types and numbers of times infrastructure support was used by each firm. We thus computed the weights corresponding to each firm's use of TT services, and employed these weights to allocate the monetary values that proxy to the best possible extent how much each firm benefited from the available infrastructure. Note that these two variables have been created using primary data and are specific to the firms in our sample. The next two inputs capture aspects of typical economic activity. Firms were asked to state the monetary amount of R\&D contracts ( $x_{3}$, excluding any funding from the TT), and the value of operating expenses $\left(\left(x_{4}\right.\right.$, excluding wages - a component of the job creation variable $\left(y_{3}\right)$ - and any expenses covered by the TT).

On the outputs side, we define revenues $\left(y_{l}\right)$ as the total income received, which represents the primary source of earnings and cash flows associated with operating activities. Moreover, most accounting definitions converge on the fact that generating revenues is the ultimate (short or long run) goal of the firm. To reach the complete regional perspective described in the theoretical underpinnings we then introduce the number of patents $\left(y_{2}\right)$, and the number of jobs created $\left(y_{3}\right)$ (computed as the sum of full time employees and half of the part time ones, the result of which is read as total full time employees). Both $\left(y_{2}\right)$ and $\left(y_{3}\right)$ are included as two separate outputs that represent-according to the conceptual framework - two key objectives to pursue when instituting regional support programmes. All inputs and outputs are at their 2007 levels. Provided that the sample comprises young firms with significant activity fluctuations during their initial market phases, we assume that growth levels may be approximated by the 2007 absolute value. This decision is also recommended by the high amount of zero values encountered for the first years of activity, and constrained by the availability of the primary data essential for this study.

Next, as indicated by previous literature, tests were run for identifying potential outliers. It is well established that extreme points may influence the shape of the estimated efficiency frontier and produce bias in the obtained scores. The seminal contributions of Andersen and Petersen (1993) and Wilson (1993) are generally employed for outlier detection. Potential outliers are identified through super-efficiency scores, and are sequentially removed from the sample and each time the efficiency is re-estimated. Additionally, as proposed by Prior and Surroca (2010), this process is repeated until the null hypotheses of equality between successive efficiency scores cannot be rejected. After eliminating outliers the final sample is composed of 81 spin-offs.

Finally, let us provide a simple numerical example to enhance the efficiency interpretation introduced in Section 4.1 and explained with the help of Figure 2. For illustrative purposes, suppose that a fictitious firm has the following input and output vectors: $\left(x_{1}, x_{2}, x_{3}, x_{4}, y_{1}, y_{2}, y_{3}\right)=(200,700$, 
$100,900,2500,2,8)$, and a corresponding distance function estimation $\delta=0.3$. This result indicates the inefficiency degree of the analysed unit, which is also the distance to the benchmark frontier formed by the best performers (see Figure 2 and its explanation). To be efficient (i.e. on the best practice frontier), this firm should expand revenues $\left(y_{1}\right)$ by $2500 \times 0.3=750$, patents $\left(y_{2}\right)$ by $2 \times 0.3=$ 0.6 (in practice, one more patent), and jobs $\left(y_{3}\right)$ by $8 \times 0.3=2.4$ (in practice, three more employees). It should have simultaneously used less grants $\left(x_{1}\right)$ by $200 \times 0.3=60$, and fewer support services $\left(x_{2}\right)$ by the value of $700 \times 0.3=210$. Also, it should contract $R \& D$ contracts $\left(x_{3}\right)$ by $100 \times 0.3=30$, and operating expenses $\left(x_{4}\right)$ by $900 \times 0.3=270$.

\subsection{Stages of analysis}

The remainder of this paper presents the empirical results and their subsequent discussion and implications. This is done according to the following stages of analysis. First, the efficiency results as defined by expressions (1) to (3) are presented. Second, the descriptive efficiency interpretations are further complemented with a second stage regression analysis to study the relationship between efficiency and key explanatory factors that capture the level of innovation and the different types of employed personnel, while controlling for types of spin-offs and universities of origin. One can assume the following specification:

$$
D\left(x^{k}, y^{k}\right)=\alpha+\boldsymbol{\beta} \mathbf{Z}^{\prime \mathbf{k}}+\varepsilon^{k}, k=1,2, \ldots, K,
$$

which is the approximation of a true but unknown relationship. In (4) $\alpha$ is the constant term, $\varepsilon^{k}$ a random error term (i.e. statistical noise), and $\mathbf{Z}^{\mathbf{k}}$ is a vector of variables thought to explain efficiency $\left(D\left(x^{k}, y^{k}\right)\right)$ through the parameters $\boldsymbol{\beta}$ (common for all $k$ ) that are estimated.

Literature indicates that the appropriate estimation model is a truncated regression, since the estimated efficiency results are constrained by definition to be equal to or greater than 0 (i.e. $\left.\delta^{k} \in[0, \infty)\right){ }^{11}$ For our model we substitute the true but observed regressand in equation (4), $D\left(x^{k}, y^{k}\right)$, by the estimate of the linear programming problem in (3), $\delta^{k}$. Thus, the model is now:

$\delta^{k} \approx \alpha+\boldsymbol{\beta} \mathbf{Z}^{\mathbf{k}}+\varepsilon^{k}, k=1,2, \ldots, K$,

which is estimated by maximizing its corresponding likelihood function with respect to $\left(\beta, \sigma_{\varepsilon}^{2}\right)$ and given the data.

For the firm-specific characteristics and controls, the following variables are used: number of employees from the university of origin, number of employees holding a $\mathrm{PhD}$, number of employees holding an engineering degree, number of patents divided by number of total employees, firm age and dummy variables for the university of origin and for the type of spin-off (i.e. STTU, SPU or OSU).

\footnotetext{
${ }^{11}$ We are using a truncated regression since, if applied under our sample's conditions, standard linear techniques would be conceptually wrong and parameter estimates would be inconsistent (Greene 2003).
} 
Next, a supplementary second stage analysis is run with a more entrepreneurial rather than regional focus. To observe the relation between future fundamental firm profitability and efficiency, we estimate the following OLS regression:

$(\text { EBITDA / employee })_{t}=\alpha+\boldsymbol{\theta} \boldsymbol{\delta}_{\mathbf{t}-1}^{\mathbf{k}}+\boldsymbol{\beta C O n t r o l s} \mathbf{s}_{\mathbf{t}-1}^{\prime \mathbf{k}}+\varepsilon^{k}, \quad k=1,2, \ldots, K$.

Note that the ratio of EBITDA (earnings before interests, taxes, depreciation and amortization) to total employees is an accounting measure appealing to economists who advocate for the use of fundamental profitability measures, which are difficult to manipulate by the selection of different sources of financing and accounting decisions. Therefore, firms with problems in this ratio have fundamental issues with their operating activity, and consequently with their profitability.

\section{Empirical results}

Efficiency results indicate that 15 of the analysed spin-offs (approximately $18.5 \%$ of the sample) form the best practice frontier. These have a score of 0 , while higher values indicate the degree of inefficiency. Table 2 reports the efficiency for the total sample as well as by spin-off type. Their associated distributions can be observed in the different panels of Figure 4, for each of the three spin-off types and for the total sample. One can notice that mean sample inefficiency is of 0.37 , a value consistent with the 0.35 median inefficiency level. Furthermore, percentiles illustrate the distribution of these total sample scores, with units below or at p25 experiencing rather low inefficiencies (less or equal to 0.08 ), and units at p75 or above showing high inefficiencies (greater than 0.59). In Figure 4 the scores' distribution for the total sample becomes more obvious as, for instance, one can note that many of the analysed units fall below the 0.2 inefficiency level.

[Figure 4 and Table 2 about here]

More insights into the scores' distribution are attained at spin-off type level. Propositions developed in our theoretical underpinnings suggested that the first group (i.e. STTU—spin-offs with formal technology transfer agreements) should be the most efficient ones, due to their superior level of embeddedness in the support mechanism (see also Figure 1). This is partly true. Although at mean level the inefficiency of this group is slightly higher than for the other two groups (i.e. 0.38 as compared to 0.37 and 0.35 for SPU-spin-offs that incorporate personnel from the parent university - and OSU — other spin-offs —, respectively), this is the group with the highest percentage and absolute number of efficient firms. This can be easily observed in Table 2 through the 0 value (which designates efficient units) reported at p25. Also, the same conclusion can be drawn by scrutinising Figure 4, which shows that many of the efficient firms are STTUs. However, the lower median and p75 levels of the STTUs reveal that this group also comprises many spin-offs with quite high inefficiency. Since these spin-offs are embedded to a higher degree in the university, one policy implication could be that more accurate monitoring systems from regional support institutions may be needed to check for extreme cases ex ante and ex post transfer agreements. In contrast, the other two 
groups have similar mean inefficiencies and, even if at p25 the OSUs are more efficient, at p75 inefficiency is roughly the same. Moreover, the second and third panels of Figure 4 illustrate that, while the OSUs have a higher relative number of efficient firms, in absolute terms the SPUs include more efficient firms (as well as more firms with higher inefficiency).

[Table 3 about here]

Results by university of origin are presented in Table 3. Rankings can be devised to include all universities, however, considering that many of these comprise very low numbers of observations one should focus on the first four institutions. Scores at all levels indicate that most of the efficient spinoffs or spin-offs showing lower inefficiencies originated from UPC and La Salle. Both include firms with the lowest mean, median and p75 inefficiency levels, and furthermore put forth efficient spinoffs at their associated p25 levels. These results are in line with our theoretical propositions, as UPC and La Salle are universities with more technological background than their counterparts and are thus expected to be better at selecting and supporting successful projects. Methods used at these universities' TT offices could be carefully reviewed for potentially generalised use that may reduce the heterogeneity observed, for instance, among STTUs. At the opposite extreme, spin-offs from UAB show the highest inefficiencies both at mean and at percentile levels, and are followed by firms from UB that have slightly (but not significantly) higher efficiency levels. Among the rest of the analysed universities, URV and IESE have the best results. Nevertheless, a maximum of two spin-offs originated from these last five universities, making it is rather difficult to interpret efficiency.

[Table 4 about here]

Next, regression analyses use efficiency estimates as dependent variables to reveal the relationships between this assessment of regional objectives and various firm characteristics. The explanatory variables and controls are introduced as described in Section 4.3. ${ }^{12}$ Our key independent variables are employees from the university of origin, the different types of personnel and patents divided by total number of employees. ${ }^{13}$

Main findings from Table 4 indicate that having more employees from the university of origin is related to less inefficiency (see the negative sign in the parameter estimate). This is yet another result in line with our propositions derived from the theoretical background of the study (see also Figure 1), and appears consistently so in specifications (1) and (2), which also reveal that the \% of PhDs or engineers has no significant relation with efficiency. However, in model (3) one observes that what seems to matter more is having $\mathrm{PhDs}$ from the university of origin (see the significant and

\footnotetext{
${ }^{12}$ For robustness, we have also run truncated regressions with bootstrap (2,000 replications) and results did not change their tenor.

${ }^{13}$ Note that patents/employees is a variable that is not present in the efficiency analysis. Both patents and number of employees appear as outputs in equations (1) to (3) and therefore their ratio is not computed. Furthermore, keep in mind that for the model in equation (3) more output (e.g. more patents or a higher number of employees) does not imply higher efficiency.
} 
negative coefficient of the interaction term "workers from university $\times \%$ of $\mathrm{PhDs}$ "). ${ }^{14}$ These findings initially suggest that academic knowledge is not necessarily useful in the market $(\mathrm{PhD}$ and engineer degrees not significant), which is consistent with existing literature that indicated a need of upgrading management skills (see, e.g., Chapple et al. (2005)). Still, specific academic knowledge or experience related with the university of origin seems to make a difference when employees hold $\mathrm{PhD}$ degrees and also are from the university of origin. This type of employees could have a competitive edge when gaining market experience, which is known to positively affect efficiency (see, e.g., Alvarez and Crespi (2003)). Indeed - in both theoretical and practical terms - it seems that retaining a $\mathrm{PhD}$ from the university of origin to continue working in the firm could create an interaction between embedded resources and specific capabilities that is positively related to efficiency (see Figure 1). On a related note, Criaco et al. (2013) analyse Catalan TT firms and find that using university human capital enhances spin-offs survival. However, their approach is fundamentally different from ours, since they focus only on founders' human capital and exclusively on firm survival, without linking it to regional objectives or the related spin-offs' efficiency.

Another result consistent with the conceptual framework is the negative relationship between patents/employees and inefficiency. That is, a higher ratio of number of patents per employees leads to lower inefficiency. Moreover, the parameter estimate of this variable is rather high in all three models. To corroborate these results, observe in Figure 5 how-for each spin-offs' category and for the total sample - higher efficiency is associated with higher number of patents. Also, extreme results such as very high inefficiency levels are related with very low number of patents. All these outcomes involving the role of innovation are in line with our theoretical foundations (to name just a two of the many studies, see Ireland et al. (2001) or Shane (2004)).

[Figure 5 about here]

Observe next that dummy variables for the university of origin show that spin-offs for UPC and La Salle have lower inefficiencies. This confirms the descriptive statistics and upholds the proposition that universities with more technological background produce more efficient spin-offs. An interesting result is that spin-offs with formal technology transfer agreements (STTU) are associated with a positive and significant coefficient, meaning that less efficient firms belong to this group. This upholds the mean or median results in the descriptive statistics in Table 2. Nevertheless, keep in mind that the STTU group also contains most efficient units, which are now truncated from the distribution. This result is a clear illustration of how the two stages of the analysis complement each other. Controls for firm age and activity area are not significant. ${ }^{15}$ Failing to find significant parameter estimates linked to the controls for activity area supports the assumption of a homogenous technology defined through the specific variables for this sample of spin-offs.

[Table 5 about here]

\footnotetext{
${ }^{14}$ The correlation between these two variables is 0.054 and it is not statistically significant.

${ }^{15}$ Models including controls for activity area are not presented in Table 5 for the sake of brevity.
} 
A last set of empirical results takes a more entrepreneurial (i.e. individual firm) rather than regional development (i.e. local institutions) perspective. Table 5 presents the relation between future fundamental profitability and its relation to efficiency. Expectations are met as we find a negative relationship between inefficiency from a regional development perspective and EBITDA/employee. Results become significant when two lags are used (i.e. efficiency in 2007 and profitability in 2009, specifications (2) and (4)). Accordingly, firms may well require about two years for generating profits from improvements in efficiency. This result is relevant for the entrepreneur, as it reveals that higher efficiency from a regional perspective is positively associated with higher medium-term fundamental profitability, which on most occasions indicates that no crucial problems exist with respect to core operating activities. Note also that results are robust to controlling for firm age and size (number of employees), as well as, alternatively, for type of spin-offs and university of origin.

\section{Concluding remarks and policy implications}

Recent literature highlights the importance of support mechanisms for venture creation, and the potential value added of regional programmes for university spin-offs. However, there is still little evidence on how to operationalize regional objectives into resources used to produce regional value. Managerial economics frameworks assume that specific resources' (inputs') configurations determine regional value added (outputs). We contribute to the regional studies literature in at least two ways: (1) we detect and conceptualise the specific regional objectives and the associated inputs and outputs needed to assess the efficiency of firms created at university-based support units, and (2) we provide in-depth empirical insights into a regional support programme.

We first propose that, from a regional perspective, firms need not only to maximise revenuesa general objective for survival and growth - but also to generate patents and jobs. The two latter variables represent main long term goals of regional institutions. Simultaneously, policy makers face budget constraints and must use inputs efficiently. We thus also account for minimising the employed resources from support programmes, which are mainly represented by financial aid and available infrastructure. This latter point is of increased importance on the background of the financial crisis, as (Spanish) deficit control measures instituted during the economic downturn specifically aimed at minimising R\&D spending. Moreover, we also allow for the presence of private sources of funding. Given this multidimensionality of inputs and outputs, we rely on directional distance functions that yield a global efficiency measure that matches the regional goals. ${ }^{16}$

We empirically assess spin-offs created within the so-called Technological Trampolines' (TTs) placed at Catalan universities. This regional setting is ideal given the pre-crisis $R \& D$ investment propensity of the region. Additionally, we benefit from a sample with homogenous technology in

\footnotetext{
${ }^{16}$ Our specification is also less restrictive and assumes variable returns to scale, given that previous literature found or directly assumed decreasing (Chapple et al. 2005) or constant returns to scale (Siegel et al. 2003).
} 
terms of available resources and regional objectives, but with different levels of embeddedness into TTs and universities. Results have a benchmarking nature, which is appealing to policy makers who can pinpoint which types of spin-offs are best practices and how different characteristics or locations are associated with efficiency. At a cursory overlook, spin-offs from the programme show a survival rate of $73 \%$ at the end of 2011, rather high given the financial distress endured during 2008-2011.

Our proposals indicate that greater degrees of innovation experience and embeddedness in the supporting institutions is associated with higher efficiency. Indeed, descriptive results show that the best practice frontier is mostly shaped by spin-offs with formal technology transfer agreements. Also, many of the efficient spin-offs originated from universities with more technological background, thus indicating that institutional experience in innovation is positively associated with achieving regional goals. Since in these cases spin-offs are embedded to a higher degree at the TT and university levels, one regional policy implication is that institutional monitoring systems should thoroughly check for extreme cases ex ante and ex post transfer agreements. Practices from thriving universities' TTs could be reviewed for potential generalised use that may reduce heterogeneity among supported spin-offs.

The second stage analyses the proposals on the types of employed personnel and innovation. We find that employing university workers is associated with higher efficiency. While PhDs do not seem to make a difference, having $\mathrm{PhDs}$ from the university of origin is related with higher efficiency. In this sense, retaining a $\mathrm{PhD}$ from the university of origin may generate a positive interaction between embedded resources and capabilities (see Figure 1). It may well be that academic knowledge is not always useful in the market (see, e.g., Chapple et al. (2005)), but academic knowledge jointly with experience at the university of origin may matter for regional objectives. This is in line with the more narrow approach of Criaco et al. (2013) who, without specific links to regional goals or efficiency, find that Catalan TT firms' survival rate is greater if founders are university members. Management skills may need upgrading (Chapple et al. 2005), but PhDs could have a competitive edge when gaining experience, which is positively related to efficiency (Alvarez and Crespi 2003).

Yet another policy implication builds on the proposed positive relation between patents (in absolute and relative, size controlled, terms) and efficiency. It could therefore be useful for local administrations to provide incentives for patent development. ${ }^{17}$ Patents may be used as a difficult to imitate signalling technique for efficient firms. Indeed, this could serve as another component of the aforementioned monitoring policy proposal for regional development. In fact, we show that when taking longer term view results demonstrate a positive relation between efficiency according to regional objectives and fundamental profitability in the second subsequent year.

There are a series of limitations to our work. The specificity of the support programme and employed variables restricts the sample to data available on spin-offs from Catalan universities. For

\footnotetext{
${ }^{17}$ These incentives may well arrive in the form of additional capital provided by regional institutions. Such policies might generate productive specialization and their impact could be compared with the results obtained for Spanish regions by Maudos et al. (2000) or Badunenko and Romero-Ávila (2012).
} 
homogeneity reasons (detailed in the theoretical underpinnings, and method and sample description) the multidimensional efficiency measure cannot be computed for a panel. We do however add data on survival and profitability for more subsequent years. Thus, we can comprehensively assess the sample and compare efficiency between the different spin-offs' characteristics, but are unable to compare against other reference groups. On the one hand, attaining these in-depth regional support programme interpretations differentiates our study from the contributions of, e.g., Harrison and Leitch (2010) or Ortín-Ángel and Vendrell-Herrero (2014).

On the other hand, a policy implication for corroborating of our results in future research on more comprehensive samples and time periods is to create databases with detailed longitudinal data on regional support programmes. In this way, reference groups (from the same region or elsewhere) could be identified and some of our proposals may be extended. Studies could assess the long run impact of retaining PhDs. Databases could be matched across regions to determine whether it is correctly assumed that supportive regional environments are catalysts for efficiency. Indeed, proper resource allocation (e.g. more funding for generating patents) and selection criteria (e.g. supporting spin-offs with formal transfer agreements) could enhance the value of regional programmes. While our policy recommendations aim at desirable outcomes, research also indicates that regional support for higher technology brings about greater coordination costs (Zabala-Iturriagagoitia et al. 2007).

Note that our selection and monitoring arguments could be scrutinised in future research that adopts an evolutionary economics perspective. Policy making for investments in regional support programmes obviously benefits from the competitive evolution of knowledge on firm and region mechanics. These rational evolutionary processes are crucial for designing institutions and enhancing competition and productivity (see, e.g., Nelson and Winter (1982) or the more recent efforts of Winter (2002) for evolutionary processes and production theory). These views may be integrated in research on regional clusters and worker mobility. For instance, existing literature introduced models of cumulative innovation with endogenous technology spillovers generated via worker turnover (see, e.g., Fosfuri and Rønde (2004)). Another connected evolutionary perspective is whether institutions aim at creating more surviving technology firms - as the CIDEM has tried via the TTs - or at finding star firms, as it many times happens at US universities that can benefit from extensive venture capital.

\section{Acknowledgements}

We thank two anonymous referees for most constructive comments that substantially improved the paper. This research received support from the Spanish Ministry of Science and Innovation through grant ECO2010-18967. Mircea Epure acknowledges financial support from the Spanish Ministry of Economy and Competitiveness, through the Severo Ochoa Programme for Centres of Excellence in R\&D (SEV-2011-0075). Usual disclaimers apply. 


\section{References}

ACC1Ó, 2011. Informe anual de la R+D i la Innovació a Catalunya 2011. http://premsa.gencat.cat/pres_fsvp/docs/2011/09/16/20/22/6403c56f-cdd0-4bf5-909b60321eb1a6d3.pdf. Accessed 27 October 2011.

Acs, Z.J., Audretsch, D.B., 1988. Innovation in Large and Small Firms: An Empirical Analysis. American Economic Review 78(4), 678-690.

Acworth, E., 2008. University-Industry Engagement: The Formation of the Knowledge Integration Community (KIC) Model at the Cambridge-MIT Institute. Research Policy 37(8), 1241-1254.

Ahedo, M., 2006. Business System and Cluster Policies in the Basque Country and Catalonia (19902004). European Urban and Regional Studies 13(1), 25-39.

Alvarez, R., Crespi, G., 2003. Determinants of Technical Efficiency in Small Firms. Small Business Economics 20(3), 233-244.

Andersen, P., Petersen, N.C., 1993. A Procedure for Ranking Efficient Units in Data Envelopment Analysis. Management Science 39(10), 1261-1264.

Anderson, T.R., Daim, T.U., Lavoie, F.F., 2007. Measuring the Efficiency of University Technology Transfer. Technovation 27(5), 306-318.

Anokhin, S., Wincent, J., Autio, E., 2011. Operationalizing Opportunities in Entrepreneurship Research: Use of Data Envelopment Analysis. Small Business Economics 37(1), 39-57.

Badunenko, O., Romero-Ávila, D., 2012. Productivity Growth across Spanish Regions and Industries: A Production-Frontier Approach. Regional Studies, forthcoming, (iFirst, doi: 10.1080/00343404.2012.709611).

Barney, J.B., 1991. Firm Resources and Sustained Competitive Advantage. Journal of Management 17(1), 99-120.

Birley, S., 1987. New Ventures and Employment Growth. Journal of Business Venturing 2(2), 155165.

Briec, W., 1997. A Graph Type Extension of Farrell Technical Efficiency Measure. Journal of Productivity Analysis 8(1), 95-110.

Buesa, M., Hiejs, J., Martinez M., Baumert, T., 2006. Regional System of Innovation and the Knowledge Production Function: The Spanish Case. Technovation 26(4), 463-472.

Carayannis, E.G., Rogers, E.M., Kurihara, K., Allbritton, M.M., 1998. High Technology Spin-offs from Government R\&D Laboratories and Research Universities. Technovation 18(1), 1-11.

Carayol, N., Matt, M., 2004. Does Research Organization Influence Academic Production? Laboratory Level Evidence from a Large European University. Research Policy 33(8), 10811102 .

Chambers, R.G., Färe, R., Grosskopf, S., 1996. Productivity Growth in APEC Countries. Pacific Economic Review 1(3), 181-190. 
Chapple, W., Lockett, A., Siegel, D., Wright, M., 2005. Assessing the Relative Performance of U.K. University Technology Transfer Offices: Parametric and Non-parametric evidence. Research Policy 34(3), 369-384.

CIDEM (Centre for Innovation and Business Development), 2006. Support for entrepreneurs Financing and subsidies. http://www.cidem.com/cidem/eng/suport/financing/index.jsp. Accessed on August 30, 2006.

CIDEM (Centre for Innovation and Business Development), 2008. Xarxa de Trampolins Tecnològics. http://www.cidem.com/cidem/cat/comunitats/xtrampolins/index.jsp. Accessed on October 21, 2008.

Clarysse, B., Wright, M., Lockett, A., Van de Velde, A., Vohora, A., 2005. Spinning Out New Ventures: A Typology of Incubation Strategies from European Research Institutions. Journal of Business Venturing 20(2), 183-216.

Criaco, G., Minola, T., Migliorini, P., Serarols, C., 2013. “To Have and Have Not': Founders' Human Capital and University Start-up Survival. Journal of Technology Transfer, DOI 10.1007/s10961-013-9312-0.

Cromie, S., 1991. The Problems Experienced by Young Firms. International Small Business Journal 9(3), 43-61.

Debackere, K., Veugelers, R., 2005. The Role of Academic Technology Transfer Organisations in Improving Industry Science Links. Research Policy 34(3), 321-342.

Denrell, J., Fang, C., Winter, S.G., 2003. The Economics of Strategic Opportunity. Strategic Management Journal 24(10), 977-990.

Di Gregorio, D., Shane, S., 2003. Why Do Some Universities Generate More Start-ups than Others? Research Policy 32(2), 209-227.

Drucker, P.F., 1985. Innovation and Entrepreneurship. Harper and Row: New York.

Dubini, P., 1989. The Influence of Motivations and Environment on Business Start-ups: Some Hints for Public Policies. Journal of Business Venturing 4(1), 11-26.

Etzkowitz, H., 1998. The Norms of Entrepreneurial Science: Cognitive Effects of the New University-Industry Linkages. Research Policy 27(8), 823-833

Etzkowitz, H., 2003. Research Groups as 'Quasi Firms': The Invention of the Entrepreneurial University. Research Policy 32(1), 109-121.

Etzkowitz, H., 2004. The Evolution of the Entrepreneurial University. International Journal of Technology and Globalization 1(1), 64-77.

Fosfuri, A., Rønde, T., 2004. High-tech Clusters, Technology Spillovers, and Trade Secret Laws. International Journal of Industrial Organization 22(1), 45-65.

Foss, N.J., Ishikawa, I., 2007. Towards a Dynamic Resource-based View: Insights from Austrian Capital and Entrepreneurship Theory. Organization Studies 28(05), 749-772.

Grant, R.M., 2008. Contemporary Strategy Analysis. $6^{\text {th }}$ ed. Blackwell: Malden.

Greene, W., 2003. Econometric Analysis. $5^{\text {th }}$ ed. Prentice Hall: New Jersey. 
Harmon, B., Ardichvili, A., Cardozo, R., Elder, T., Leuthhold, J., Parshall, J., Raghian M., Smith, M., 1997. Mapping the University Tranfer Process Process. Journal of Business Venturing 12(5), 423-434.

Harrison, R.T., Leitch, C., 2010. Voodoo Institution or Entrepreneurial University? Spin-off Companies, the Entrepreneurial System and Regional Development in the UK. Regional Studies 44(9), 1241-1262.

Hawkins, D.I., 1993. New Business Entrepreneurship in the Japanese Economy. Journal of Business Venturing 8(2), 137-150.

Hindle, K., Yencken, J., 2004. Public Research Commercialisation, Entrepreneurship and New Technology Based Firms: An Integrated Model. Technovation 24(10), 793-803.

Ireland, R.D., Hitt, M.A., Camp, L., Sexton, D.L., 2001. Integrating Entrepreneurship and Strategic Management Actions to Create Firm Wealth. Academy of Management Executive 15(1), 49-63.

Jacob, M., Lundqvist, M., Hellsmark, H., 2003. Entrepreneurial Transformations in the Swedish University System: The Case of Chalmers University of Technology. Research Policy 32(9), 1555-1568.

Kirchhoff, B.A., Phillips, B.D., 1988. The Effect of Firm Formation and Growth on Job Creation in the United States. Journal of Business Venturing 3(4), 261-272.

Lockett, A., Siegel, D., Wright, M., Ensley, M.D., 2005. The Creation of Spin-Offs at Public Research Institutions: Managerial and Policy Implications. Research Policy 34(7), 981-993.

Ma, H., Tan, J., 2006. Key Components and Implications of Entrepreneurship: A 4-P Framework. Journal of Business Venturing 21(5), 704-725.

Matkin, G., 1990. Technology Transfer and the University. Macmillan Publishing, New York.

Maudos, J., Pastor, J.M., Serrano, L., 2000. Efficiency and Productive Specialization: An Application to the Spanish Regions. Regional Studies 34(9), 829-842.

Mustar, P., Renault, M., Colombo, M.G., Piva, E., Fontes, M., Lockett, A., Wright, M., Clarysse, B., Moray, N., 2006. Conceptualising the Heterogeneity of Research-Based Spin-offs: A MultiDimensional Taxonomy. Research Policy 35(2), 289-308.

Nelson, R.R., Winter, S., 1982. An Evolutionary Theory of Economic Change. Cambridge: Harvard University Press.

Nicolaou, N., Birley, S., 2003. Academic Networks in a Trichotomous Categorisation of University Spinouts. Journal of Business Venturing 18(3), 333-359.

Ortín-Ángel, P., Vendrell-Herrero, F., 2014. University Spin-Offs vs. other NTBFs: Total Factor Productivity Differences at Outset and Evolution. Technovation 34(2), 101-112.

Pavitt, K., Robson, M., Townsend, J., 1987. The Size Distribution of Innovating Firms in the UK: 1945-1983. Journal of Industrial Economics 35(3), 297-316.

Penrose, E.T., 1959. The Theory of the Growth of the Firm. Wiley, New York.

Pérez, M., Martínez, A., 2003. The Development of University Spin-offs: Early Dynamics of Technology Transfer and Networking. Technovation 23(10), 823-831. 
Peretaf, M., 1993. The Cornerstones of Competitive Advantage: A Resource-Based View. Strategic Management Journal 14(3), 179-191.

Pirnay, F., Surlemont, B., Nlemvo, F., 2003. Toward a Typology of University Spin-offs. Small Business Economics 21(4), 355-69.

Prior, D., Surroca, J., 2010. Performance Measurement and Achievable Targets for Public Hospitals. Journal of Accounting, Auditing and Finance 25(4), 749-766.

Ray, S.C., 2004. Data Envelopment Analysis: Theory and Techniques for Economics and Operations Research. Cambridge University Press, New York.

Serarols, C., Urbano, D., Vaillant, Y., Bikfalvi, A., 2009. Research Commercialisation via Spin-Off: The Case of a Non-Elite University. International Journal of Technology Transfer and Commercialisation 8(4), 356-378.

Sexton, D.L., 1986. Role of Entrepreneurship in Economic Development. In Hisrich, R.D. Entrepreneurship, Intrapreneurship, and Venture Capital. D.C. Heath y Company: Massachusetts, Ch.2, 27-39.

Shane, S.A., 2004. Academic Entrepreneurship: University Spinoffs and Wealth Creation. Edward Elgar Publishing, Cheltenham, UK.

Siegel, D.S., Waldman, D., Link, A., 2003. Assessing the Impact of Organisational Practices on the Relative Productivity of University Technology Transfer Offices: An Exploratory Study. Research Policy 32(1), 27-48.

Steffensen, M., Rogers, E.M., Speakman, K., 2000. Spin-offs from Research Centers at a Research University. Journal of Business Venturing 15(1), 93-111.

Storey, D.J., 1994. Employment. In Storey, D.J. Understanding the Small Business Sector. Routledge: London, Ch.6, 160-203.

Teece, D.J., 2007. Explicating Dynamic Capabilities: The Nature and Microfoundations of (Sustainable) Enterprise Performance. Strategic Management Journal 28(13), 1319-1350.

Teece, D.J., Pisano, G., Shuen, A., 1997. Dynamic capabilities and strategic management. Strategic Management Journal 18(7), 509-533.

Thursby, J.G. Kemp, S., 2002. Growth and Productive Efficiency of University Intellectual Property Licensing. Research Policy 31(1), 109-124.

Vohora, A., Wright, M., Lockett, A., 2004. Critical Junctures in the Development of University HighTech Spinout Companies. Research Policy 33(1), 147-135.

Wennekers, S., Thurik, R., 1999. Linking Entrepreneurship and Economic Growth. Small Business Economics 13(1), 27-55.

Wernerfeldt, B., 1984. A Resource Based View of the Firm. Strategic Management Journal 5(2), 171180.

White, S.B., Reynolds, P.D., 1996. Government Programs and High Growth New Firms. In Frontiers of Entrepreneurship Research. Babson College, US. 
Wilson, P.W., 1993. Detecting Outliers in Deterministic Nonparametric Frontier Models with Multiple Outputs. Journal of Business \& Economic Statistics 11(3), 319-323.

Winter, S., 2002. Toward and Evolutionary Theory of Production. LEM Working Paper Series no. $2002 / 27$.

Wright, M., Vohora, A., Lockett, A., 2004. The Formation of High Tech University Spinout Companies: The Role of Joint Ventures and Venture Capital Investors. Journal of Technology Transfer 29(3/4), 287-310.

Zabala-Iturriagagoitia, J.M., Voigt, P., Gutiérrez-Gracia, A., Jiménez-Sáez F., 2007. Regional Innovation Systems: How to Assess Performance. Regional Studies 41(5), 661-672. 
Figure 1: Spin-off type embeddedness at university Technological Trampolines (TTs)

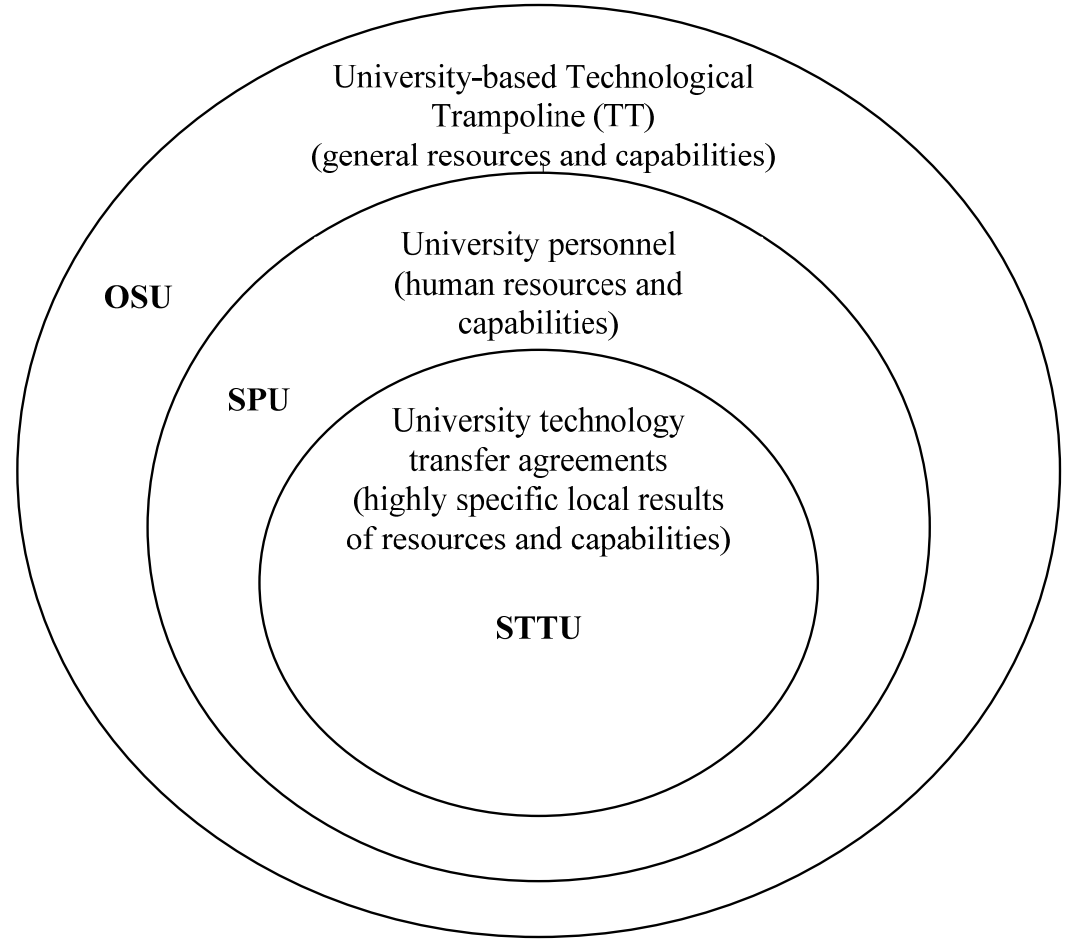

Figure 2: Efficiency measure: The proportional distance function

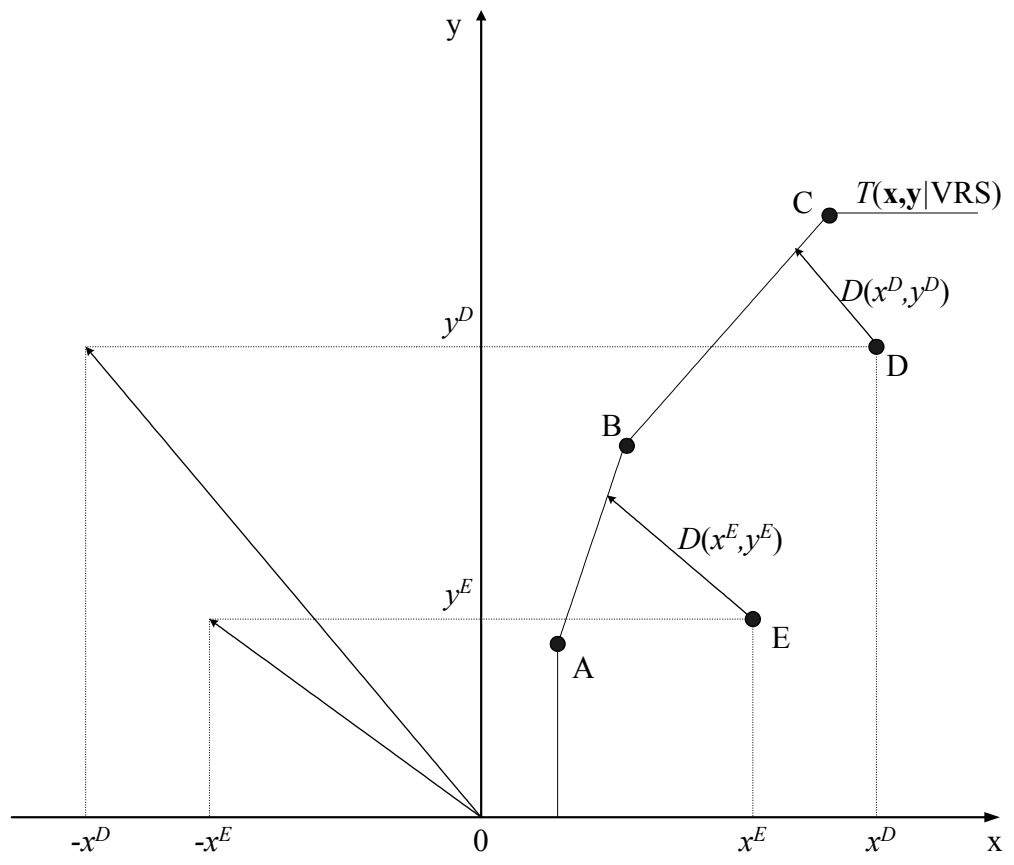

Figure 3: Inputs and outputs: A regional studies perspective

\section{Inputs}

$\left(x_{1}\right)$ Grants (economic aid) (reg. develop.)

$\left(x_{2}\right)$ Services used (reg. develop.)

$\left(x_{3}\right)$ Funds received from other

$\mathrm{R} \& \mathrm{D}$ contracts (economic)

$\left(x_{4}\right)$ Operating expenses (economic)

\section{Outputs}

$\left(y_{1}\right)$ Revenues generated (economic)

$\left(y_{2}\right)$ Patents generated (reg. develop.)

$\left(y_{3}\right)$ Jobs created (economic and reg. develop.) 
Figure 4: Distribution of efficiency levels (by total sample and spin-off types)

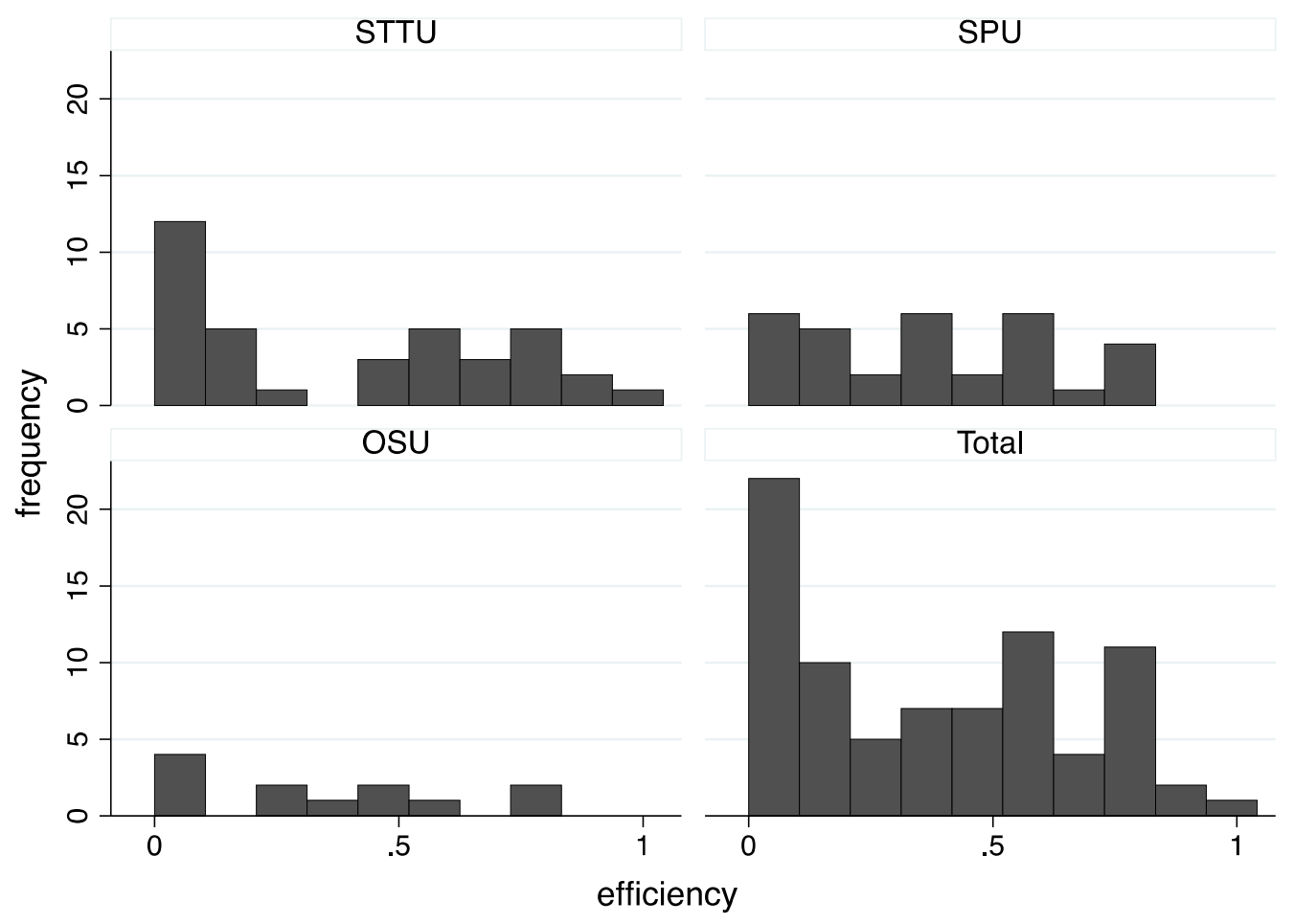

Figure 5: Efficiency and number of patents (by total sample and spin-off types)

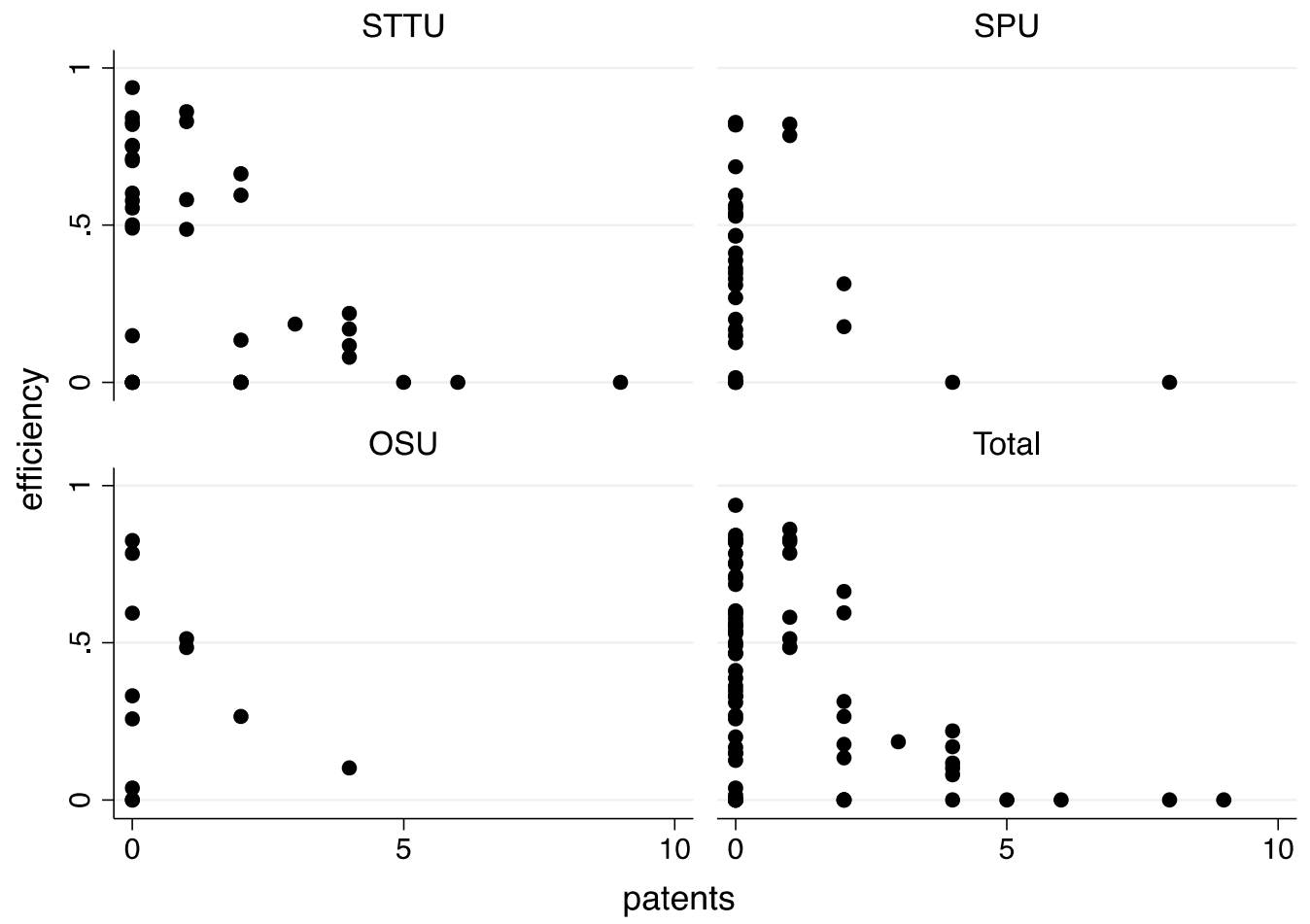


Table 1: Inputs and outputs: descriptive statistics

\begin{tabular}{lrrr}
\hline Inputs and Outputs & Mean & $\begin{array}{r}\text { 5\% Trimmed } \\
\text { Mean }\end{array}$ & Std. Dev. \\
\hline$\left(x_{1}\right)$ Grants (economic aid) $(€)$ & 27321.21 & 14527.00 & 76446.08 \\
$\left(x_{2}\right)$ Services used $(€)$ & 70625.68 & 67910.45 & 53228.31 \\
$\left(x_{3}\right)$ R\&D contracts $(€)$ & 23862.96 & 11325.79 & 64301.90 \\
$\left(x_{4}\right)$ Operating expenses $(€)$ & 222246.20 & 143742.19 & 438045.20 \\
$\left(y_{1}\right)$ Revenues generated $(€)$ & 394853.40 & 270030.96 & 727482.60 \\
$\left(y_{2}\right)$ Patents generated (no.) & 1.02 & 0.75 & 1.85 \\
$\left(y_{3}\right)$ Jobs created (no.) & 8.23 & 7.07 & 8.12 \\
\hline
\end{tabular}

Table 2: Efficiency by spin-off type and total sample

\begin{tabular}{lrrrrrr}
\hline Spin-off type & Obs. & Mean & Std. Dev. & p25 & Median & $\boldsymbol{p 7 5}$ \\
\hline STTU & 37 & 0.3822 & 0.3389 & 0.0000 & 0.4869 & 0.7048 \\
SPU & 32 & 0.3669 & 0.2634 & 0.1582 & 0.3548 & 0.5439 \\
OSU & 12 & 0.3495 & 0.2921 & 0.0697 & 0.2982 & 0.5534 \\
Total & 81 & 0.3713 & 0.3007 & 0.0802 & 0.3475 & 0.5951 \\
\hline
\end{tabular}

Table 3: Efficiency by university of origin and total sample

\begin{tabular}{lrrrrrr}
\hline University of origin & Obs. & Mean & Std. Dev. & $\boldsymbol{p 2 5}$ & Median & $\boldsymbol{p 7 5}$ \\
\hline Univ. Autònoma Barcelona (UAB) & 13 & 0.5132 & 0.2704 & 0.3621 & 0.5525 & 0.7048 \\
Univ. Politècnica Catalunya (UPC) & 21 & 0.3058 & 0.2762 & 0.0000 & 0.3099 & 0.4909 \\
Univ. de Barcelona (UB) & 8 & 0.4623 & 0.3277 & 0.1517 & 0.5566 & 0.6723 \\
La Salle & 31 & 0.3152 & 0.2908 & 0.0000 & 0.2653 & 0.5809 \\
Univ. de Girona (UdG) & 2 & 0.5059 & 0.4539 & 0.1850 & 0.5059 & 0.8269 \\
ESADE & 2 & 0.7352 & 0.0704 & 0.6855 & 0.7352 & 0.7850 \\
Univ. Pompeu Fabra (UPF) & 2 & 0.5150 & 0.4448 & 0.2005 & 0.5150 & 0.8295 \\
Univ. Rovira i Virgili (URV) & 1 & 0.0000 &. &. &. &. \\
IESE & 1 & 0.0000 &. &. &. &. \\
Total & 81 & 0.3713 & 0.3007 & 0.0802 & 0.3475 & 0.5951 \\
\hline
\end{tabular}


Table 4: Efficiency and its relation to spin-offs' characteristics

\begin{tabular}{|c|c|c|c|c|c|c|}
\hline \multirow[b]{2}{*}{ Variable } & \multicolumn{2}{|l|}{ (1) } & \multicolumn{2}{|l|}{ (2) } & \multicolumn{2}{|c|}{ (3) } \\
\hline & Coef. & $\begin{array}{l}\text { Std. } \\
\text { error }\end{array}$ & Coef. & $\begin{array}{l}\text { Std. } \\
\text { error }\end{array}$ & Coef. & $\begin{array}{l}\text { Std. } \\
\text { error }\end{array}$ \\
\hline univ. empl. & $-0.029^{*}$ & 0.015 & $-0.026^{*}$ & 0.015 & -0.016 & 0.014 \\
\hline$\%$ of phd & & & -0.002 & 0.002 & & \\
\hline$\%$ of bsc in engineering & & & 0.001 & 0.001 & & \\
\hline univ. empl. $\times \%$ of phds & & & & & $-0.001 * * *$ & 0.000 \\
\hline patents / empl. & $-0.860 * * *$ & 0.210 & $-0.809 * * *$ & 0.203 & $-0.777 * * *$ & 0.196 \\
\hline uab & & & -0.153 & 0.141 & -0.127 & 0.139 \\
\hline upc & & & $-0.262 * *$ & 0.133 & $-0.282 * *$ & 0.131 \\
\hline la salle & & & $-0.265^{*}$ & 0.137 & $-0.294 * *$ & 0.129 \\
\hline $\mathrm{ub}$ & & & -0.180 & 0.156 & -0.206 & 0.150 \\
\hline firm age & -0.008 & 0.019 & -0.020 & 0.019 & -0.018 & 0.018 \\
\hline sttu & $0.250^{* *}$ & 0.121 & $0.235^{*}$ & 0.130 & $0.210^{*}$ & 0.124 \\
\hline spu & -0.022 & 0.116 & -0.059 & 0.118 & -0.107 & 0.114 \\
\hline cons & $0.522 * * *$ & 0.101 & $0.773 * * *$ & 0.203 & $0.831 * * *$ & 0.160 \\
\hline obs. & 66 & & 66 & & 66 & \\
\hline log likelihood & 10.10 & & 13.53 & & 14.13 & \\
\hline Wald chi2 & 21.08 & & 28.36 & & 30.04 & \\
\hline prob $>$ chi2 & 0.001 & & 0.003 & & 0.001 & \\
\hline
\end{tabular}

Truncated regressions; truncated at lower limit (0); 15 efficient units truncated Dependent variable: efficiency; efficient units have scores of 0 , values $>0$ report the inefficiency degree. All variables are at their 2007 levels. $*, * *$ and $* * *$ stand for significant statistical differences at $90 \%, 95 \%$ and $99 \%$ confidence levels, respectively.

Table 5: Fundamental profitability and its relation to efficiency

\begin{tabular}{|c|c|c|c|c|c|c|c|c|}
\hline \multirow[b]{2}{*}{ Variable } & \multicolumn{2}{|c|}{$\begin{array}{c}\text { (1) Dep. var.: } \\
\text { EBITDA/empl. } \\
2008\end{array}$} & \multicolumn{2}{|c|}{$\begin{array}{c}\text { (2) Dep. var.: } \\
\text { EBITDA/empl. } \\
2009\end{array}$} & \multicolumn{2}{|c|}{$\begin{array}{c}\text { (3) Dep. var.: } \\
\text { EBITDA/empl. } \\
2008\end{array}$} & \multicolumn{2}{|c|}{$\begin{array}{c}\text { (4) Dep. var.: } \\
\text { EBITDA/empl. } \\
2009\end{array}$} \\
\hline & Coef. & $\begin{array}{l}\text { Std. } \\
\text { error }\end{array}$ & Coef. & $\begin{array}{l}\text { Std. } \\
\text { error }\end{array}$ & Coef. & $\begin{array}{l}\text { Std. } \\
\text { error }\end{array}$ & Coef. & $\begin{array}{l}\text { Std. } \\
\text { error }\end{array}$ \\
\hline efficiency & -12524.8 & 8753.1 & $-27934 * * *$ & 10336.8 & -10877 & 8670.4 & $-27475.4^{* *}$ & 10255.6 \\
\hline firm age & 1657.1 & 1383.1 & -428.16 & 1565.9 & 1233.5 & 1413.9 & -1019.4 & 1590.9 \\
\hline no. empl. & 297.5 & 358.5 & -95.8 & 406.4 & 446.2 & 364.8 & 91.8 & 413.6 \\
\hline sttu & & & & & 785.7 & 8056.5 & 7002.7 & 9507.3 \\
\hline spu & & & & & 11148.3 & 8456.8 & 16624.3 & 9996.6 \\
\hline cons & 2024.8 & 6150.3 & \multicolumn{2}{|c|}{$20295.7 * * * 7261.5$} & -3320.7 & 8847.6 & 10390.9 & 10406.8 \\
\hline obs. & \multicolumn{2}{|c|}{69} & \multicolumn{2}{|l|}{65} & \multicolumn{2}{|c|}{69} & \multicolumn{2}{|l|}{65} \\
\hline $\mathrm{F}$ & \multicolumn{2}{|c|}{2.71} & \multicolumn{2}{|l|}{2.61} & \multicolumn{2}{|c|}{2.46} & \multicolumn{2}{|l|}{2.33} \\
\hline Prob $>F$ & \multicolumn{2}{|c|}{0.052} & \multicolumn{2}{|l|}{0.060} & \multicolumn{2}{|c|}{0.042} & \multicolumn{2}{|l|}{0.053} \\
\hline R-squared & \multicolumn{2}{|c|}{0.111} & \multicolumn{2}{|l|}{0.114} & \multicolumn{2}{|c|}{0.163} & \multicolumn{2}{|l|}{0.165} \\
\hline
\end{tabular}

OLS regressions. Dependent variables for each model are indicated in the first row. Independent variables are at their 2007 levels. $*, * *$ and $* * *$ stand for significant statistical differences at $90 \%, 95 \%$ and $99 \%$ confidence levels, respectively. Specifications controlling for university of origin have also been run and the tenor of the results does not change. 